\title{
The Location of Digital Ethnography
}

\author{
Dana M. Walker \\ Univer sity of Michigan
}

\begin{abstract}
Qualitative researchers interested in digitally-located social and cultural practices have struggled with ways in which to design studies that can account for the digital aspect of cultural practices while also taking into account that those digital practices do not exist as separate (or separable in terms of our research) from other social and cultural practices. As such, one of the primary and ongoing challenges facing internet-based ethnographic research is the question of how to construct the location of a project when the sites, technologically-mediated practices, and people we study exist and flow through a wider information ecology that is neither fixed nor can easily be located as "online” or "offline." This is as much a methodological challenge as a theoretical one. If one accepts that a rigid distinction between online and offline makes little theoretical sense, then drawing a methodological line between online and offline only reifies such a dualism. While there is a developing body of internet-related ethnographic literature which is attempting to take into account the fluid nature of our information ecology (e.g. Burrell 2009, Leander and McKim 2003, Hine 2007), we continue to operate on shifting ground. This article uses the case of my own work on city-specific discussion forums in Philadelphia, Pennsylvania to highlight the complexities of locating digital ethnographic work and also argue for the necessity of accounting for both movement and placed-ness.
\end{abstract}

\section{Introduction}

Qualitative researchers interested in digitally-located social and cultural practices have struggled with ways in which to design studies that can account for the digital aspect of cultural practices while also taking into account that those digital practices do not exist as separate (or separable in terms of research) from other social and cultural practices. As such, one of the primary and ongoing challenges facing internet-based ethnographic research is the question of how to construct the location of a project when the sites, technologicallymediated practices, and people we study exist and flow through a wider information ecology that is neither fixed nor can easily be located as "online” or "offline.” There has been a growing body of scholarship focusing in a more serious way on how digital technologies fit within people's daily practices - how such technologies are integrated within the practices that constitute families and communities (e.g. Wellman and Haythornthwaite 2002) or how internet-based technologies augment or remediate our sense of physical place (Crang et al. 2007). 
This embedded, everyday quality of digitally-based practices and our attempts to study them is as much a methodological challenge as a theoretical one. And while constructing the field site has always been a methodological concern to ethnographers, those studying digital life find such locating practices uniquely complicated in a setting where the researcher often does not occupy the same physical space as the participants. There is a developing body of internet-related ethnographic literature which is attempting to take into account the fluid nature of our information ecology (e.g. Burrell 2009, Leander and McKim 2003, Hine,2007); however, we continue to operate on shifting ground.

This article uses the case of my own research on city-specific discussion forums in Philadelphia, Pennsylvania (US) to highlight the complexities of locating digital ethnographic work and also argue for the necessity of accounting for both movement and placed-ness. My work has focused on the meanings and experiences that emerge around the internet in the context of civic use - researching what happens when people engage in everyday civic discussions in online city-specific forums. In particular, the work has focused on what meanings and interpretations participants in these geographically-based discussion forums construct for themselves on local political issues, civic identity, and the construction and organization of civic space. The focus on the meaning-making work that accompanies the use of information and communication technologies has placed the work squarely within a grouping of internet studies that focus on technologically-mediated practices from the standpoint of the users of the technology (e.g. Bakardjieva 2005, Orgad 2006, boyd 2008), following user practices rather than particular technologies.

My project entailed a multi-sited ethnographic study of internet-enabled civic talk and focused on city-specific online sites primarily in one geographic location: Philadelphia, Pennsylvania. Hammersley and Atkinson (2007) usefully describe ethnography in terms of what researchers actually do, explaining that ethnography usually involves "the researcher participating, overtly or covertly, in people's daily lives for an extended period of time, watching what happens, listening to what is said, and/or asking questions through informal and formal interviews, collecting documents and artefacts - in fact, gathering whatever data are available to throw light on the issues that are the emerging focus of inquiry” (p. 3). 
Like many ethnographies, during my 18 months of fieldwork I observed numerous online city-focused and neighborhood-based sites, attended "offline” civic meetings and events, and interviewed local civic organizers, journalists, and academics. I wanted to see civic practices moving on and offline. Unlike much work focusing on online civic and political discussion that is either national in scope or interested in particular technological applications, my focus was partly geographical. I was interested in the ways in which online-enabled discussions were constructing and organizing civic places. I therefore needed to locate the field site so that it accounted for the fluid nature of internet practices, but did so without privileging such fluidity over the geographic place in which such practices emerged.

In a very particular sense, I wanted to explore the ways in which internet-enabled practices are articulated in local, city and neighborhood specific civic activity. So while I had as a field site a geographic space, my study examined virtual spaces which articulated but did not necessarily fit the Cartesian properties of that geographic location. Borrowing from Jenna Burrell's (2009) notion of “intercept,” I conceptualized the field as a network of relations in which a cluster of city-specific online discussion forums served as a hub of inquiry.

The article unfolds in three sections. First, I consider some of the problems and dilemmas researchers have faced in constructing field sites in online environments. Second, I take up approaches to account for movement in fluid informational ecologies and look specifically at notions of mobile or multi-sited ethnography. Third, I describe my own online/offline field site as a way to explore and ground the challenges of conducting digital ethnographies. I describe structuring my fieldwork by using an intercept and look particularly at the choices I made to enter the field and the ways in which I accounted for the geographical located-ness of the study.

\section{Problems: Constructing the Field Site}

A set of fieldwork boundaries is the outcome of a project, rather than its precursor. The decision about when to start and stop, and where to go in between, is for ethnographers not made independently of the field, but is an intrinsic part of the relationship to it (Hine 2009, p. 18).

How do we construct the location of a project when what we study - the sites and technologically-mediated practices - flow through a vast ecology that is also fluid? The internet, in particular, makes a neat distinction between online and offline exceptionally 
complicated because, as Bakardjieva notes, it is the very place where the "online and offline meet” (2009, p. 54). Put simply, the social phenomena we study - the identity construction of teenagers (boyd 2008); how cancer patients cope with their disease (Orgad 2005); or even how sociability is constructed in text-based environments (Rutter and Smith 2005) - do not live exclusively in one particular realm but instead exist, become entwined, and disentangle in a continuous flow through any number of mediated environments. Even making the claim that one studies "The Internet” as if it were a unified or static phenomenon is problematic (Slater 2002) since, in reality, "the” internet is a mix of software; hardware; already-built infrastructures; as well as social, cultural, political and legal practices which combine, become stabilized, and are articulated in different places and under different contexts.

This is as much a methodological challenge as a theoretical one. If one accepts that a rigid distinction between online and offline makes little theoretical sense, then drawing a methodological line between online and offline only reifies such a dualism. For the purposes of ethnographic research, the challenge has been to configure a field site that can take into account interconnected and overlapping mediated contexts but in a way as to make the project coherent, manageable and defensible. The field site is not something that is decided upon once and for all at the start of a project, but instead decisions about inclusion and exclusion are made continuously throughout study (Burrell 2009). Amit describes the problem as an issue of not "discovering” but rather "constructing” the field site, arguing: "the ethnographic field cannot simply exist, awaiting discovery. It has to be laboriously constructed, prised apart from all the other possibilities for contextualization to which its constituent relationships and connections could also be referred” (Amit 2000, p. 6).

The realization that the field site is constructed rather than discovered (Amit 2000) or is the outcome rather than precursor of research (Hine 2008) is a crucial theoretical aspect of ethnographic work in digital contexts. This methodological challenge has been approached variously and is tied to theoretical developments within the field of internet studies. Reviewing the scholarship, Christine Hine (2000) has distinguished two distinct understandings of the internet as (1) a culture in its own right and (2) as a cultural artifact. Each view, she argued, carries with it its own analytic advantages and affiliated notions of what would be considered an appropriate field site. 
In the first, the internet is a place in and of itself, containing within it a set of norms and practices to be studied (or at least that could be studied) without reference to people's unmediated, or offline, lives. This conceptualization is one of the earlier theoretical constructions in which the internet is described as a distinct place with a specific cultural dynamic that one goes to. For example, early in the development of the internet as a mass communication medium, Rheingold (1993) in his writing about his experiences with the WELL (Whole Earth 'Lectronic Link) asserted that internet-based communication could provide richer forms of interaction and spaces for deep and meaningful "virtual community" formation. A common early methodological approach, then, was to define the field site as a distinct internet-based technology - a newsgroup, multi-player online gaming site, or social networking software application - and to study that site as a more or less self-contained phenomena.

The second of Hine's categories is the internet-as-cultural-artifact perspective, which she develops within a framework of the sociology of science and technology. This perspective involves seeing the internet as the product of culture, co-configured by objects and social contexts and shaped by the ways in which it is used, marketed and taught (2000 p. 9), thus having multiple identities and interpretations. Under this conceptualization, the internet exists within a broader cultural, social, political and legal context. It is not a separate system of existence, but instead has rooted within everyday life in important ways. In their notable analysis of the embeddedness of the internet in daily life, Haythornthwaite and Wellman argued the "pervasive, real-world Internet does not function on its own, but is embedded in the real-life things that people do" and argued that one of the great "sins" of early internet research was to think of it as a "lived experience distinct from the rest of life" (2002 pp. 5-7). Similarly, Miller and Slater in their ethnographic study of the internet in Trinidad, critiqued analyses that focused on virtuality and separateness as the defining feature of the internet, claiming instead that the extent to which people treat internet relations as unconnected from their everyday lives is something that required explanation, being "treated as a practical accomplishment rather than the assumed point of departure for investigation” (2000 pp. 5-6).

As such, a collection of influential critiques have challenged what was once an assumed division between online and offline (e.g. Leander and McKim 2003, Haythornthwaite and Wellman 2002, Carter 2005, Miller and Slater 2000), establishing instead a view of internet- 
enabled practices as being embedded in everyday life. With this grounding, internet ethnographies have adopted different strategies and notions of what constitutes an appropriate field site. Hampton and Wellman (2003), for example, conducted an offline ethnography of a Toronto suburb in order to understand how internet connectivity enhanced a sense of neighborhood by facilitating contact between residents who were loosely connected. Also focusing primarily on an offline environment, Bakardjieva (2005) studied the integration of the internet into the everyday lives of users by focusing on ethnographic interviews and observation in domestic settings. Others have started in the online realm, focusing all or at least most of their attention there. Boellstorff (2008) constrained his fieldwork completely within the virtual world Second Life in order to understand forms of social action and meaning-making that take place within it; while TL Taylor (2006) followed the same trajectory as her research subjects, participating first in online gaming and then joining players to observe them during their in-person meet-ups.

\section{Theories: Multi-sited Ethnography}

Increasingly as a way to account methodologically for the blurred relationship between online and offline, ethnographers of internet practices have employed mobile or multi-sited ethnographic methods, advocating the analyst follow the movement or trace the flow of “objects, texts, and bodies” as they move between mediated and unmediated environments (Leander and McKim 2003). First conceptualized in cultural anthropology, multi-sited ethnography is a response to several decades of methodological reflection by ethnographers who questioned the notion that a field site was a bounded geographic space that contained whole, intact, and knowable cultures (Gupta and Ferguson 1992 as cited in Burrell 2009). Marcus (1995), among others, argued that culture was not necessarily spatially fixed but was constituted by global flows made up “in/of the world system.” As such, ethnographic methods must account for those flows, writing that this mode of ethnographic research:

... moves out from the single sites and local situations of conventional ethnographic research designs to examine the circulation of cultural meanings, objects, and identities in diffuse time-space. This mode defines for itself an object of study that cannot be accounted for ethnographically by remaining focused on a single site of intensive investigation. (1995, p. 96)

Marcus forwards "tracking strategies” as a way to provide a coherent research project, including: "follow the people;" "follow the thing” (material object); "follow the metaphor;" 
"follow the plot;" "follow the biography;" and "follow the conflict." The argument for such a mobile approach highlights the centrality of movement and connectedness in social practice. It foregrounds the notion that social processes take place across distance-connecting any range of distinct entities (Burrell 2009).

In terms of internet research, multi-sited ethnography - in particular Marcus’s tracking strategy of "following the thing," can provide a methodological approach that accounts for the role of material objects (technologies, artifacts, media) in describing social processes that are constituted in and articulated through sociotechnical practices. Conventionally, ethnographic research has concentrated primarily on the role of human actors in meaningmaking processes. While documents and artifacts have certainly been part of ethnographic projects, those objects have often been examined as the product, and not a co-producer of, culture. The result is that technology often plays a limited role in understanding social practices, a point Bruno Latour makes arguing that technical objects are the "missing masses" in social science (1992).

Latour and colleagues develop the idea of the centrality of objects as a component of the social in ethnographic work emerging from science and technology studies. Marcus (1995) himself contends that the emergence of multi-sited ethnography is located, in part, in interdisciplinary scholarship such as media studies and science and technology studies and cites Latour's ethnographic work as case in point of "following the thing." One of the critical assertions of Latour is that we think of society and technology as one heterogeneous collective, composed of people together with technology, machines, and things. It is the interaction among these heterogeneous objects which constitute society and these interrelationships are conceived as networks of human and non-human actors, each of which is itself a network of heterogeneous things (Doolin and Lowe 2002). The key methodological contribution of such a construct is the notion that actors are constantly moving, interacting, changing, and in flow and the job of the researcher is to "trace" those objects as they circulate in the network.

Furthermore, multi-sited ethnography's focus on movement helps to dissolve the coupling of the fieldworker's physical location as being coterminous with the field site - providing a break between "physical presence and spatial experience” (Burrell 2009). Traditionally, 
ethnography has been conceptualized as a geographically bounded project - dwelling in a particular locale for periods of time and participating in the social practices of those locations. From this (traditional) perspective, ethnographic methods are oddly matched to the research spaces of the internet which have blurry (at best) geographic boundaries: site contributors in one location, readers in another, servers and site designers in a third. A focus on movement, tracings and flows is provocative for thinking about studies of internet-enabled practices precisely because it allows the conduct of fieldwork on social phenomena that take place across time and distance.

Researchers of internet practices have made various attempts to configure field sites so as to account for movement and connectedness. Using online traces, researchers have followed links within a field site. Beaulieu (2005), for example, used hyperlinks within a large database (the functional Magnetic Resonance Imaging Data Center) as an ethnographic object - constituting the field site by following hyperlink traces and also reflecting on how those links were both functionally created and symbolically understood. In her study of the scientific discipline of biological systematics, Hine (2007) employed what she calls a “connective ethnography,” and explored the connections between different activities including group message exchange, institutional observation, interviews, and hyperlink paths. For Hine, a key starting or entry point was a mailing list which she used as a source of data and complement to interviews. In her study of teens use of social networking sites for identity creation and management, boyd (2008) uses a form of networked ethnography in which she analyzes the MySpace profiles of teens throughout the United States and interviews teens as to their mediated practices.

In each of these approaches, connection and movement are critical methodological concerns of the project with the boundaries of the field site being constructed by: an infrastructure of knowledge production (e.g. functional Magnetic Resonance Imaging Data Center), discipline (e.g. biological systematics), or social media application (e.g. Facebook and MySpace). My own work focused on the use of the internet in civic meaning-making and as such I have been interested in the ways in which information technologies, particularly internet-enabled ones, are integrated into the public construction of meaning as well as the construction of a space in which civic practices can be enacted. In a very particular sense, I wanted to explore the ways in which internet-enabled practices are articulated in local, city and neighborhood specific 
civic activity. So while I had as a field site a geographic space, my study examined virtual spaces which articulated but did not necessarily fit the Cartesian properties of that geographic location. I wanted to understand internet-enabled practices as related to a geographic place, but not reify those geographic boundaries by claiming my field site was the city of Philadelphia.

If one examines the theoretical work that has emerged from the field of human geography, it is clear that those working specifically on issues of place and space no longer regard them as so easily bounded or separable from the information and communication networks that operate within or through them. For example, Massey writes, "the particularity of place is...constructed not by placing boundaries around it and defining its identity through counterposition to the other that lies beyond, but precisely (in part) through its specificity of the mix of links and interconnections to that 'beyond'” (1994, cited in Kellerman 2002, p.40). Other scholars, including urban sociologists, architects, and communications researchers have echoed these insights, arguing for the need to see places as constructed through the convergences of many kinds of networked connections, including economic transactions, information loops, and the movement of people. Manuel Castells (2000) integrates these perspectives into his celebrated argument about the shift to a networked society, one in which the "space of flows" has emerged and to a certain extent superseded the traditional "space of places." Still, we need not concede the continued importance of physical location, or suggest that differences between places have been dissolved. It is possible to arrive at a more restrained conclusion: that choosing a field site has always meant a choice of immersion within particular networks and connections, whether it has been expressly acknowledged by the researcher or not.

\section{Reflections: The Online/Offline Field Site}

The main research question with which I entered the field was the extent to which information technologies, particularly internet-enabled ones, are integrated into the civic meaning-making process - both in the construction of political public meaning making as well as the construction of a space in which civic practices are enacted. I did not start the project by focusing on one, bounded online site. Rather, I approached the field as a network (Burrell, 2009) and conceptualized the project by thinking of it in terms of the phenomenon I 
was interested in studying: the intersection of civic meaning-making and information and communication technologies.

Because of my interest in civic practices and the co-construction of civic places through information technologies, I entered the field by focusing on a single geographic area: Philadelphia, Pennsylvania. Such an approach allowed me to look deeply at a limited civic context and enabled a combination of online and offline qualitative work. Theoretically, Philadelphia provided a fruitful research site in part because of its abundance and diversity of neighborhoods, many of which have an active online presence. In a city of 1.5 million people and covering 135 square miles, neighborhoods matter. While it has become cliché, people have long referred to Philadelphia as a "city of neighborhoods." The 1995 edition of the Philadelphia Almanac and Citizens’ Manual documented 395 different names for various neighborhoods throughout the city - 200 of which are still used. To a greater or lesser extent, these distinct neighborhoods support an extensive and historic civic infrastructure in the form of neighborhood and civic associations, community development corporations, neighborhood planning councils, and a range of ad hoc civic groups. Some of this organizational civic structure transferred to an online environment as early as the mid-1990s ${ }^{1}$ with many neighborhood-based groups supporting websites, distribution and discussion email lists (and rival neighborhood groups supporting splinter lists), and later Yahoo Groups, blogs, and Facebook pages.

While Philadelphians often talk proudly of their "city of neighborhoods," the negative potential for parochialism this creates is referred to almost as frequently. Despite being the sixth largest city in the nation, it is customary to hear stories of native Philadelphians who rarely leave their neighborhoods. Attempts to link neighborhood organizations have existed in the city at least since the 1970s with projects such as the now-extinct Philadelphia Council of Neighborhood Organizations. Those linking attempts moved online as early as 1995 at which time the Institute for the Study of Civic Values created Neighborhoods Online ${ }^{2}$ and later Phillyblocks. ${ }^{3}$ The sites provided information about city-wide issues and political

\footnotetext{
${ }^{1}$ See, for example, Ed Schwartz's (Schwartz, 1998) description of the Neighborhoods Online project in which the Institute for the Study of Civic Values attempted to connect and disseminate information about neighborhood organizations.

${ }^{2}$ http://www.neighborhoodsonline.net/

${ }^{3}$ http://phillyneighborhoods.org/index.html
} 
developments - compiling information from the distinct neighborhood associations in a consolidated space with the intention of linking community groups (Schwartz 1998).

In addition to an online presence by traditional organized civic groups, there was a growing online blogosphere representing what then New York University journalism chair Jay Rosen identified as one of the more active blogging cities in the country (Oxfeld 2005). The range of city-based blogs reflected the diversity of the blog genre in general: hyper-local news to individually-authored place-based accounts of neighborhood life; "watchdog” blogs on city government, Philadelphia's metroblogging site; and city gossip blogs. There have also been several successful attempts at aggregating Philadelphia's hyper-local online writing and commenting. Homegrown PhillyFuture.org has a "Philly wire" service that compiles online writers, blogs, and commentators in the Philadelphia region. While the later developed multicity Everyblock.com collects news articles, blog entries, and other civic information and maps it to a geographic location.

Despite such a strong online civic presence, I struggled to define a manageable field site. Early in my research, I tracked neighborhood email lists from different parts of the city. Reading such hyper-local news and commentary sites as well as the neighborhood distribution lists was a critical part of mapping various online civic practices in the city. However, most of these resources were unidirectional and my interest was in meaningmaking through the back-and-forth discussions among city residents about the problems, resources, experiences, and opinions of the city.

\section{Using an "intercept"}

Based on interviews and observation, an active site for the discussion of neighborhoods was a large, multi-topic threaded message board entitled Phillyblog.com. The site was in existence from 2002-2009. Despite the misnomer, Phillyblog was not a blog but an internet forum that was divided into 41 broadly-defined boards that covered geographic neighborhoods as well as topical areas (e.g. politics, spirituality). On busy days, about 1,000 registered users would login to the site with the most registered users ever online in one day being nearly 4,000 (site administrator, interview). Like many forums (also called message boards or bulletin boards), Phillyblog employed a threaded conversational structure composed of threads and replies to those threads. Discussion threads could be initiated by any registered user and the most 
current discussion thread appeared on the forum's landing page. The bulk of the communication was publicly visible, searchable, and archived, though participation could involve anonymous or pseudonymous contributions.

Importantly for my work, Phillyblog was a location where a range of civic groups, citizens, and even journalists looked for civic information. It became a central component of my inquiry based on initial fieldwork and an early appreciation of the scope, diversity, volume and discursive activity in the site; its recognition in the city as a location to talk and get information about neighborhoods and city-wide concerns; and the variety of civic information it manifested. Borrowing from Jenna Burrell’s work on internet cafés in Accra, Ghana, I saw Phillyblog as an "intercept point" - an intersection through which civic life flowed. Phillyblog experienced a constant circulation of users and topics. So as users moved in and out of the site, I moved with them: following their links to other discussion, civic, or institutional sites in the city and travelling with them to the places in the city that they were discussing. Studying the site as a point of intersection of users and topics structured my work in three critical ways: (a) the way I treated - an analysis and presentation - data that had been collected from multiple sources including "online” and "offline”; (b) the ways in which I travelled with participants as they moved on and offline; and (c) the ways in which both my informants and I entered into the field site.

\section{(a)“Online” and "Offline” Data}

Using an intercept and tracing movements online and offline meant that I had to think about how I would collect, analyze, and ultimately present data I encountered in different locations. Because I was trying to account for flow from on to offline, I wanted to make sure I was able to collect and triangulate data that I encountered online and offline. I was a participant observer of the site and therefore collected data in the form of digitally-born Phillyblog postings. I lived in the city of Philadelphia and as an ethnographer was collecting and analyzing artifacts I encountered in my own “offline” realm (e.g. newspapers, community bulletins, etc.). Finally, I conducted interviews via three different media: in-person, via the telephone, or over email.

In empirical analysis, I combined data from all sources - regardless of how it was collected. Indeed, I cannot distinguish if interview data, digital thread data, or observation was more or 
less influential in my analysis since ultimately my understanding emerged from observation and analysis of threads, was reformulated based on interviews, and then became more nuanced when I looked at additional threads. As a result, I opted to treat the data similarly in analysis. In other words, I did not assume that interview data was more valid or "real" than data I encountered digitally. I was not interested in whether or not people were somehow "truthfully" representing themselves. Rather, I was interested in how they were making sense of their civic lives. In my presentation, I did indicate the location in which $I$ encountered the data - either in digital threads or in interviews. Some researchers have used different font types to distinguish data collected online versus that offline (Orgad, 2009), but I did not feel it was necessary (and indeed seemed counterproductive) to do so.

\section{(b) Travelling: Understanding the Digital Layer atop the Material Spaces of the City}

Using an intercept, secondly, meant that I could examine the connections of Phillyblog posts to physical locations in the city; but I did not have to physically follow all of those connections. Instead of travelling to the various civic locations that participants discussed, I paid attention to the ways in which Phillyblog participants created a kind of digital layer atop their own physical space by locating their digital posts - their first-hand accounts and experiences - within their own neighborhoods. For example, one of the most common posting practices on Phillyblog was to report micro-local news. Posters asked questions and shared information about neighborhood construction and development projects, restaurant closings and opening, scaffolding in front of buildings, and road closures - the "stuff" of everyday urban living. Commonly, those reports were first-hand accounts of crime. In a thread entitled, “Car Break-In 17 ${ }^{\text {th }}$ \& Brandywine,” posted in one of Phillyblog's 14 neighborhood boards, was typical of the types of threads which appeared on the site daily.

Just wanted to warn everyone that my car was broken into at 17 th \& Brandywine last night. It was around 9:15 and I had just parked my car, came into the house and not even 5 min. later heard the alarm going off. I looked out the window to see 2 young men running away from it. Be careful when you park (thread 15763, \#1).

Posters would also solicit others to report on neighborhood activities. In the University City forum, a user asked: “Anyone know why two helicopters were flying over around 50th and Chester last night around 11pm?” (thread 15765, \#1). These kinds of first-hand reports and warnings were almost always "mapped,” in the sense that they included specific coordinates 
(e.g. $17^{\text {th }} \&$ Brandywine). As individual posts, this activity is comparable to a police blotter: a running list of corners of the city where one might take care when parking or walking. But commonly such posts did not exist on their own - they were accompanied by an ensuing set of responses, observations, or analysis of the problem. On a thread concerning gunfire in the Graduate Hospital neighborhood of Philadelphia, a poster originated a thread with "There were about six shots fired at 22nd \& Fitzwater at 6:30. A guy was shot in the leg” (thread 16963, \#1). Over the course of two days, 134 replies were made to the thread in which neighbors argued that there was an increasing trend of crime at the intersection because of increased drug activity:

This was bound to happen as many people have posted over the past few months that suspicious characters seemed to be congregating at 22nd and Fitzwater (thread 16963, \#5).

This was followed by a response asking:

Anyone have any ideas as to what we might do to curb the loitering and associated problems on the stretch of 22nd between Fitzwater and Catharine? (thread 16963, \#7).

In the successive 130 posts, there was a discussion opened up regarding what neighbors might do collectively. One participant researched and posted all the abandoned buildings in the area. Another disseminated telephone numbers for the public housing authority and community police. Another suggested a letter writing campaign to city council members and the mayor in which they provided sample copy for fellow neighbors. I never physically travelled to these particular street corners. But by using a digital intercept, I was able to analyze the ways in which Phillyblog participants were digitally annotating the material places in which they lived.

\section{(c) Entry Points to the Field and to Civic Life}

The final, and third, critical way that an intercept structured my own work was that it helped spotlight the ways in which interview participants themselves were using Phillyblog as an entry point into the civic life of the city. A common posting practice was for newcomers to the city to ask about neighborhoods in which they might relocate. It became such a frequent posting practice, that one enterprising Phillyblogger created a questionnaire that he asked neighborhood home-seekers to fill out so that others would be able to better help them. The 
form included questions about the most basic, but critical issues of urban life: do you need to park a car; how long are you willing to commute; do you have kids or dogs; do you want walking access to grocery stores, restaurants, museums? Other participants described their online conversations as a way to almost "jumpstart" a relationship to the city - learning about the city, its problems, and its resources in detailed ways that may not have been possible without their participation on the site. For example, one participant who had only lived in the city for three and half years explained: "I feel like I know a lot more about the city than I would as a resident who lived here three and a half years and didn't read it. I feel better informed about things going on in the city about differences from neighborhoods to neighborhoods” [interview].

\section{Conclusion}

Structuring the fieldwork using an intercept was critical for practical reasons - the civic discussions on Phillyblog moved to physical locations that would have been difficult or impossible for me to travel to because of my own limited resources of time. They also moved outside the geographic boundaries of Philadelphia, but practically I was able to maintain a relatively stationary position in following the flows on the site.

More than a practical consideration, however, using an intercept gave me access to the digital layer of the city that I would have never seen if I had not followed the circulating discourses on Phillyblog. I discovered a public layer of the city that was neither solely digital nor solely material. When I walked by a neighborhood public park, for example, I knew that it was the subject of a vigorous debate between neighbors about the appropriate use of the space - a tennis court or a dog run? Neighbors complained that dogs were defecating on the tennis courts, making it at best unpleasant and at worse unsanitary to play on the courts. Dog owners defended themselves, arguing that most owners were responsible and that they needed places to take their dogs. Materially, this appeared to be a space like many others in the city, a small pocket park in an urban neighborhood that had a tennis court and

playground. Digitally, I saw evidence of a discursive struggle to decide how to use scarce and valuable resources in a city that doesn't have much green space. And because I traveled with participants in that discursive struggle and the ways in which they linked to their civic organization by posting the results of meetings, I knew what participants already understood: they were using ICTs to debate the nature and future of their shared civic spaces. 
One of the primary rationales for using multi-sited ethnography in digital ethnography is that it can help break down a methodologically pervasive, but theoretically problematic dualism between the neat separation of online and offline. But, as described in this article, seeing the field site as constituted as a network that is moving or in flow, can also allow for an understanding of where flows of activity intersect and where they become set in a place. It is the dual aspect of the network - its moving and placed parts - that lends itself to being able to account for both movement and placed-ness.

\section{Acknowledgements}

I would like to acknowledge and thank all those participants who were extremely generous with their time in interviews and follow-up discussions. I would also like to especially thank Patrick Wehner for his valuable feedback on the project and this article.

\section{References}

Amit, V. 2000, Constructing the field: Ethnographic fieldwork in the contemporary world, Routledge, London.

Bakardjieva, M. 2005, Internet society: The Internet in everyday life, Sage, London.

Bakardjieva, M. 2009, 'A response to Shani Orgad', In: Markham, A. N. \& Baym, N. K. (eds.) Internet Inquiry: Conversations about Method, Sage, Los Angeles.

Beaulieu, A. 2005, 'Sociable hyperlinks: An ethnographic approach to connectivity', Virtual methods: Issues in social research on the Internet, 183-197.

Boellstorff, T. 2008, Coming of age in Second Life: An anthropologist explores the virtually human, Princeton Univ Pr.

boyd, d. 2008, Taken out of context: American teen sociality in networked publics. Doctor of Philosophy in Information Management and Systems, University of California, Berkeley.

Burrell, J. 2009, 'The field site as a network: a strategy for locating ethnographic research', Field Methods, vol. 21, pp. 181-199.

Carter, D. 2005, 'Living in virtual communities: an ethnography of human relationships in cyberspace', Information, Communication \& Society, vol. 8, pp. 148-167.

Crang, M., Crosbie, T. \& Graham, S. 2007, 'Technology, time - space, and the remediation of neighbourhood life', Environment and Planning A, vol. 39, pp. 2405-2422.

Doolin, B. \& Lowe, A. 2002, 'To reveal is to critique: actor-network theory and critical information systems research', Journal of Information Technology, vol. 17, pp. 6978.

Gupta, A. \& Ferguson, J. 1992 'Beyond" culture": Space, identity, and the politics of difference', Cultural Anthropology, vol. 7, pp. 6-23.

Hammersley, M. \& Atkinson, P. 2007, Ethnography: Principles in Practice, Routledge, London. 
Hampton, K. \& Wellman, B. 2003, 'Neighboring in Netville: How the Internet supports community and social capital in a wired suburb', City \& Community, vol. 2, pp. 277311.

Haythornthwaite, C. A. \& Wellman, B. 2002, 'Introduction: The Internet in Everyday Life', In: Wellman, B. \& Haythornthwaite, C. A. (eds.) The Internet in everyday life. Blackwell, Oxford.

Hine, C. 2000.,Virtual Ethnography, Sage, London.

Hine, C. 2007, 'Connective ethnography for the exploration of e-science', Journal of Computer-Mediated Communication.

Hine, C. 2009, 'How Can Qualitative Internet Researchers Define the Boundaries of Their Projects? ' In: Markham, A. N. \& Baym, N. K. (eds.) Internet Inquiry: Conversations about Method, Sage, Los Angeles.

Latour, B. 1992, 'Where are the missing masses? the sociology of a few mundane artifacts', In: Bijker, W. \& Law, J. (eds.) Shaping Technology/Building Society: Studies in Sociotechnical Change, MIT Press., Cambridge, Mass.

Leander, K. \& Mckim, K. 2003, 'Tracing the everyday 'sitings' of adolescents on the internet: A strategic adaptation of ethnography across online and offline spaces', Education Communication and Information, vol.3, pp. 211-240.

Marcus, G. E. 1995, 'Ethnography in/of the world system: the emergence of multi-sited ethnography', .Annual Review of Anthropology, vol. 24, pp. 95-117.

Miller, D. \& Slater, D. 2000, The Internet; An Ethnographic Approach, Berg, Oxford.

Orgad, S. 2005, Storytelling Online: Talking Breast Cancer on the Internet, Peter Lang Publishing, New York.

Orgad, S. 2006, 'The cultural dimensions of online communication: a study of breast cancer patients' internet spaces', New Media Society, vol. 8, pp. 877-899.

Orgad, S. 2009, 'How can researchers make sense of the issues invovled in collecting and interpreting online and offline data?' In: Markham, A. N. \& Baym, N. K. (eds.) Internet Inquiry: Conversations about Method. Sage, Los Angeles.

Oxfeld, J. 2005, 'Letting the Blogs Out', Editor \& Publisher, no. 138, pp. 39-41.

Rheingold, H. 1993, The Virtual Community: Homesteading on the Electronic Frontier, Addison-Wesley, Reading, Mass.

Rutter, J. \& Smith, G. 2005, 'Ethnographic presence in a nebulous setting', In: Hine, C. (ed.) Virtual Methods. Berg, Oxford.

Schwartz, E. 1998, 'An internet resource for neighborhoods', In: Tsagarousianou, R., Tambini, D. \& Bryan, C. (eds.) Cyberdemocracy: Technology, Cities and Civic Networks. Routledge, London.

Slater, D. 2002, 'Social relationships and identity online and offline', In: Lievrouw, L. A. \& Livingstone, S. (eds.) The Handbook of New Media. Sage, London.

Taylor, T. 2006, Play between worlds: Exploring online game culture, MIT Press, Cambridge, Mass.

Wellman, B. \& Haythornthwaite, C. A. 2002, The Internet in everyday life, Blackwell, Oxford. 